\title{
Article \\ Experimental Study on the Out-of-Plane Behavior of Brick Masonry Walls Strengthened with Mortar and Wire Mesh: A Pioneer Study
}

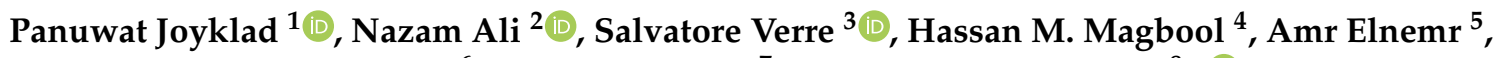 \\ Muhammad Irshad Qureshi ${ }^{6}$, Qudeer Hussain ${ }^{7}$ and Krisada Chaiyasarn ${ }^{8, *(D)}$ \\ 1 Department of Civil and Environmental Engineering, Faculty of Engineering, Srinakharinwirot University, \\ Nakhon Nayok 26120, Thailand; panuwatj@g.swu.ac.th \\ 2 Department of Civil Engineering, School of Engineering, University of Management and Technology, \\ Lahore 54770, Pakistan; nazam.ali@umt.edu.pk \\ 3 Department of Civil Engineering, University of Calabria, 87036 Cosenza, Italy; salvatore.verre@unical.it \\ 4 Civil Engineering Department, College of Engineering, Jazan University, Jazan 45142, Saudi Arabia; \\ h.magbool@jazanu.edu.sa \\ 5 Civil Engineering Program, German University in Cairo, New Cairo City 11835, Egypt; \\ amr.elnemr@guc.edu.eg \\ 6 Department of Civil Engineering, University of Engineering and Technology, Taxila 47050, Pakistan; \\ irshad.qureshi@uettaxila.edu.pk \\ 7 Center of Excellence in Earthquake Engineering and Vibration, Department of Civil Engineering, \\ Chulalongkorn University, Bangkok 10330, Thailand; ebbadat@hotmail.com \\ updates \\ Citation: Joyklad, P.; Ali, N. \\ Verre, S.; Magbool, H.M.; Elnemr, A.; \\ 8 Thammasat Research Unit in Infrastructure Inspection and Monitoring, Repair and Strengthening (IIMRS), \\ Thammasat School of Engineering, Thammasat University Rangsit, Pathumthani 12121, Thailand \\ * Correspondence: ckrisada@engr.tu.ac.th
} Qureshi, M.I.; Hussain, Q.; Chaiyasarn, K. Experimental Study on the Out-of-Plane Behavior of Brick Masonry Walls Strengthened with Mortar and Wire Mesh: A Pioneer Study. Infrastructures 2021, 6, 165. https://doi.org/10.3390/ infrastructures6110165

Academic Editor: Ali Behnood

Received: 28 October 2021

Accepted: 17 November 2021

Published: 22 November 2021

Publisher's Note: MDPI stays neutral with regard to jurisdictional claims in published maps and institutional affiliations.

Copyright: (c) 2021 by the authors. Licensee MDPI, Basel, Switzerland. This article is an open access article distributed under the terms and conditions of the Creative Commons Attribution (CC BY) license (https:// creativecommons.org/licenses/by/ $4.0 /)$.

\begin{abstract}
In the past, fiber-reinforced polymer (FRP) composites have been extensively used to modify the structural response of masonry brick walls. The promising advantages of FRP composites are easy application, lightweight, and very high tensile strength. However, FRP composites are very expensive, and their availability is an issue, especially in developing countries. The use of bricks is widespread in developing countries due to their low price and easy availability. Recent earthquakes and research results have demonstrated the vulnerability of existing masonry structures. In this study, we aimed to investigate the use of low-cost and readily available strengthening materials, i.e., cement-sand mortar and wire mesh, to enhance the flexural capacity of cement-clay interlocking brick (CCIB) masonry walls. The proposed strengthening materials were applied in different configurations and thicknesses. The experimental results indicated that using CS mortar and wire mesh is promising to enhance the flexural capacity of CCIB masonry walls. The flexural capacity and energy absorption capacity of the CCIB masonry wall (strengthened with $20 \mathrm{~mm}$ thick CS mortar and three layers of wire mesh) were $87 \%$ and $46 \%$ higher than the reference CCIB masonry wall. The results of this study can be used to improve the performance of masonry structures against earthquakes in the developing regions.
\end{abstract}

Keywords: bricks; cement; clay; energy absorption; flexural capacity; masonry walls; mortar; wire mesh; strengthening

\section{Introduction}

Earthquakes are natural calamities that pose severe threats to human lives and cause destruction of buildings and infrastructure on a massive scale. Recently, the urbanization and spread of cities have enormously taken place in most countries. Urbanization has resulted in a rapid increase in infrastructure, buildings, and bridges in almost all regions worldwide. Hence, economic and life losses related to earthquake hazards have spiked in the last few decades. Brick masonry is commonly opted throughout the world to construct 
various structures, including buildings, bridge abutments, and water tanks [1-4]. It is a fact that brick masonry structures are brittle in nature and weak against earthquake loading, particularly when they are not reinforced against seismic loadings. Unreinforced masonry structures can be inclined to experience severe damages even during a moderate intensity seismic activity. The Christchurch earthquake of 6.3 magnitude resulted in heavy damages to buildings in the city as most of the construction was established by brick masonry. Hence, this type of structure performed worst as compared with the reinforced structures $[5,6]$. Thailand is considered to be located in a relatively less seismic-prone region; however, the evidence of some severe damage due to earthquakes could be traced in the country. A 2004 earthquake and the subsequent tsunami severely struck Thailand and other countries in the region, resulting in enormous damage to infrastructure, claiming hundreds of human lives [7].

The earthquakes of 2011 in Northern Thailand and 2014 in the Mae Lao province are recent examples of moderate-intensity seismic events that caused severe damage to buildings and infrastructure. In Thailand, masonry is considered to be the essential feature in most building constructions due to its economic benefits, ease of manufacturing, construction, and durability properties [8,9] Due to the high demand for brick masonry in the construction sector, various modifications and innovations have been investigated by several researchers to enhance the properties of brick masonry [10-14]. One such innovations is interlocking brick masonry, which is now extensively used as an alternative to conventional bricks in Thailand. Cement-clay interlocking (CCI) bricks are manufactured locally in small factories $[15,16]$ and are considered to be a feasible replacement for conventional brick masonry because less cement and sand are required during placement. Various researchers have studied the performance and behavior of CCI masonry. It has been observed that, although CCI masonry structures perform well under the compressive loading [17,18], nevertheless, CCI's efficiency is not appreciable under tensile, lateral loading, and diagonal compression loading [19-21].

Several researchers have carried out experimental studies to propose strength-enhancing techniques for brick masonry and concrete structures [22-24]. These methods involve strengthening using fiber-reinforced polymer (FRP) composites and steel rods [25-30]. Although the proposed FRP composites have exhibited the enhanced load-carrying capacity of brick masonry, the high cost of FRP composites offset their benefits due to their higher cost as compared with the cheaper construction technique of brick masonry.

Therefore, low-cost alternatives to enhance the load-bearing capacity of CCI masonry structures should be explored. These materials are more efficient in terms of cost and strength than the traditionally used materials. The total strengthening cost by FRP composites is usually 100-130\% higher than the mortar or concrete jacketing. This current research work is a preliminary study to investigate the viability of various conventional strengthening methods incorporating locally available materials, i.e., cement-sand mortar and wire mesh, which are readily available, and relatively cheaper than FRP composites. Therefore, this study fills the gap in the existing literature by investigating the out-of-plane behavior of brick masonry walls strengthened with mortar and wire mesh. The findings suggest that this technique can outperform the conventional masonry structures which are produced locally. Thus, to the best of our knowledge this study is the first to investigate this particular phenomenon and behavior of masonry structures prepared with locally readily available mortar and wire mesh in Thailand. The findings of this study can be expanded and utilized for improved design of masonry structures, especially in the South-Asian region, where masonry structures are the primary source of building construction. The remainder of this paper is organized as follows: in Section 2, we describe the experimental settings used to prepare specimens and testing system; in Section 3, we discuss the main findings and results of the study; and finally in Section 4, some of the study's conclusions are summarized. Future research directions are proposed for researchers keen to explore the modified design of masonry structures. 


\section{Experimental Program}

A total of six reinforced cement-clay interlocking brick (CCIB) masonry walls were constructed and tested under three-point bending conditions to investigate the out-of-plane behavior of CCIB masonry walls. Five were externally strengthened among the six CCIB masonry walls using cement-sand (CS) mortar and wire mesh (WM). One wall was tested without any external strengthening to serve as a control or reference CCIB masonry wall. The CS mortar and wire mesh were applied in different thicknesses and configurations to investigate the effect of CS mortar thickness and the number of layers of wire mesh on the ultimate load-carrying capacity and deformation of the CCIB masonry walls. In the strengthening configuration A (Figure 1a), the CS mortar was applied on both sides of the CCIB masonry walls. The CS mortar was applied only on one side in the strengthening configuration B, as shown in Figure 1b. The details of the experimental program are given in Table 1 . The names of CCIB masonry walls were assigned to represent research parameters. The first letter indicates the masonry wall, the second letter indicates the thickness of cement-sand mortar, the third letter indicates wire mesh, and the last letter presents the number of layers of wire mesh in the CCIB masonry wall names, as shown in Table 1.

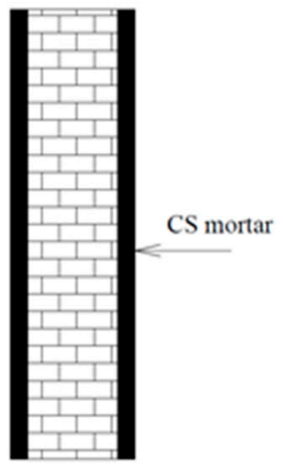

(a)

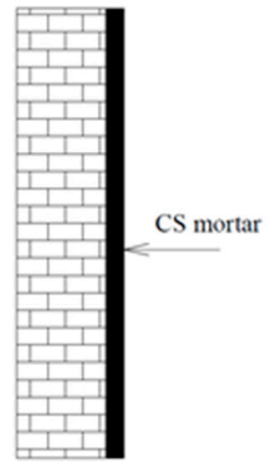

(b)

Figure 1. Typical details of strengthening configurations: (a) Configuration A; (b) configuration B.

Table 1. Details of CS mortar strengthening.

\begin{tabular}{cccc}
\hline CCIB Masonry Walls & $\begin{array}{c}\text { Thickness of CS } \\
\text { Mortar }(\mathbf{m m})\end{array}$ & Configuration & Layers of Wire Mesh \\
\hline MW-CON & - & - & - \\
MW-CS10-A & 10 & A & - \\
MW-CS20-A & 20 & A & - \\
MW-CS10-A-WM-1L & 10 & A & 3 \\
MW-CS20-A-WM-3L & 20 & A & 3 \\
MW-CS20-B-WM-3L & 20 & B & \\
\hline
\end{tabular}

\subsection{Details of Masonry Walls}

The size of the CCI-BM walls was selected as per the capacity and size of the reaction frame in the laboratory. The lengths and heights of the CCI-BM walls were $1000 \mathrm{~mm}$ (Figure 2a), and the thicknesses of the wall were equal to the thickness of CCIB, i.e., $125 \mathrm{~mm}$. Locally available CCIBs were used (Figure 2b). The CCIBM walls were all constructed using a running bond pattern (Figure $2 \mathrm{a}$ ), and circular holes were filled with the cement-sand (CS) mortar to represent existing construction practices in Thailand. Prior to the grout filling, plain bars of diameter $6 \mathrm{~mm}$ were placed in the circular holes to reinforce the CCIB masonry walls. 


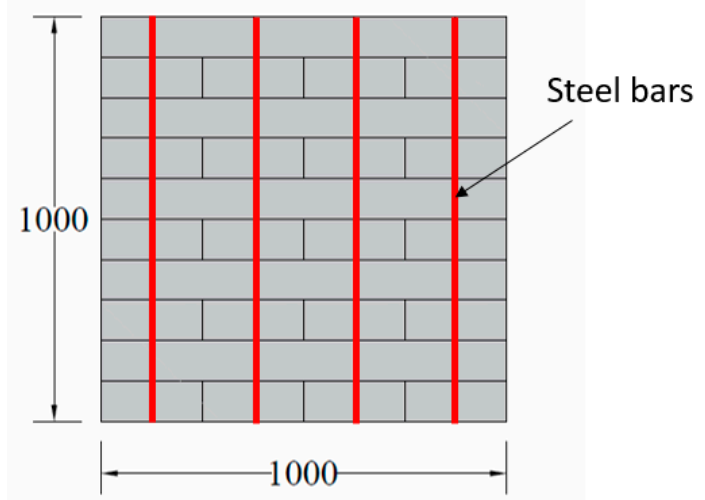

(a)

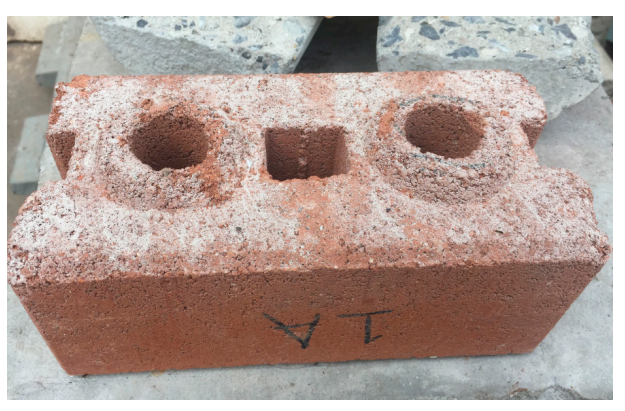

(b)

Figure 2. Typical details of the CCIB masonry wall (units, mm): (a) Wall details; (b) CCI brick.

\subsection{Material Properties}

The cement-clay interlocking (CCI) bricks were obtained from a local supplier. The standard tests were performed on CCI bricks to determine the mechanical properties such as compressive strength, tensile strength, water absorption capacity, and density [31,32]. The mechanical properties of the CCI bricks are summarized in Table 2. Locally available Type I Portland cement was used with river sand to prepare cement-sand (CS) mortar. The compressive strength of the CS mortar was determined by testing standard cubes of $50 \times 50 \mathrm{~mm}$. The average compressive strength of CS mortar was $50 \mathrm{MPa}$. The standard tensile tests were performed on round steel bars (RSB) to determine the tensile strength of round bars. The yield and ultimate tensile strength of RSB6 were $400 \mathrm{MPa}$ and $550 \mathrm{MPa}$, respectively. The shape of wire mesh used was hexagonal, in which the length and width of the hexagon were $25 \mathrm{~mm}$ and $12.5 \mathrm{~mm}$, respectively. The diameter of the steel wire was approximately $1 \mathrm{~mm}$.

Table 2. Material properties.

\begin{tabular}{cccc}
\hline Properties & Values & Units & Reference Standards \\
\hline Compressive strength & 6.70 & $\mathrm{MPa}$ & ASTM C1314 \\
Tensile strength & 0.22 & $\mathrm{MPa}$ & ASTM C1006 \\
Water absorption & 13.0 & $\%$ & ASTM C1314 \\
Density & 1850 & $\mathrm{~kg} / \mathrm{m}^{3}$ & ASTM C1314 \\
\hline
\end{tabular}

\subsection{Construction and Strengthening of Masonry Walls}

In this study, the CCIB masonry walls were constructed using a running bond pattern. In the first step, dry cement-clay interlocking bricks were stacked over each other, and in the next step, the circular and square holes were filled with CS grout. Before the grout filling, round steel bars with a diameter of $6 \mathrm{~mm}$ were placed in the square openings of the CCI bricks to reinforce the CCIB masonry walls. The CCIB masonry walls filled with CS grout were left for seven days at an ambient temperature for curing purposes, and after that, the CS mortar was applied on the CCI bricks using a conventional hand labor process (Figure 3). In the case of CS mortar and wire mesh strengthened walls, the wire mesh was attached to the CCI bricks using steel nails and washers, and then CS mortar was applied on the CCI bricks (Figure 3c). Proper care was taken to achieve the required thickness of the CS mortar. The typical strengthening process of the CCIB masonry walls is shown in Figure 3. 


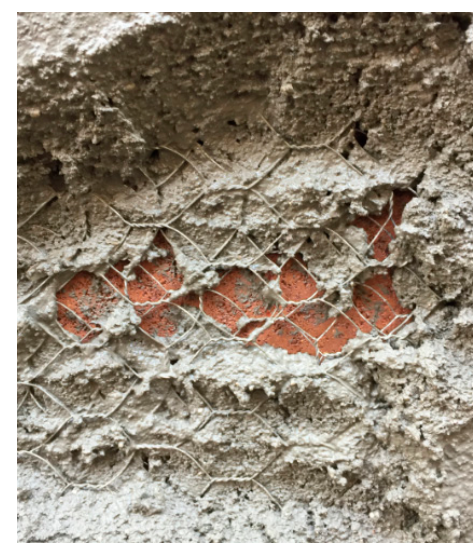

(a)

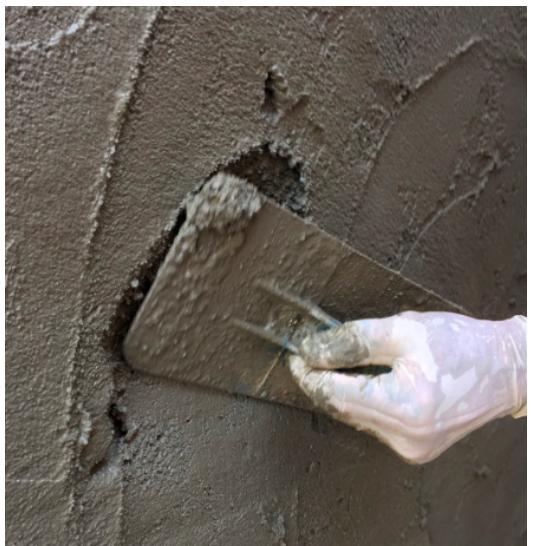

(b)

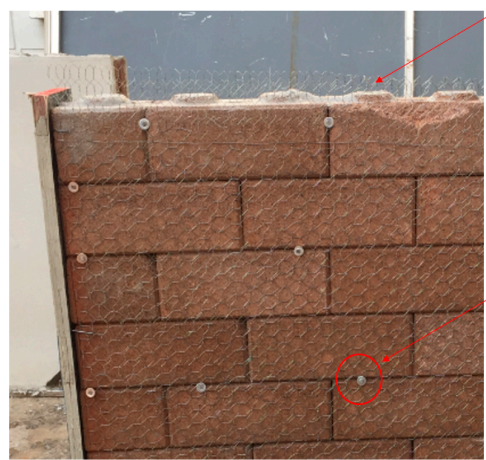

Wire mesh

(c)

Figure 3. Application of wire mesh and CS mortar: (a) Wire mesh and cement mortar; (b) cement mortar; (c) attachment of wire mesh.

\subsection{Loading Setup and Instrumentation Details}

The CCIB masonry walls were all tested under a three-point bending scheme, as shown in Figures 4-6. A rigid steel reaction frame was used to apply load at the top of the CCIB masonry walls. The maximum capacity of the reaction frame was $2000 \mathrm{kN}$. The load was applied using a hydraulic jack, as shown in Figures 5 and 6. A pre-calibrated load cell of capacity $500 \mathrm{kN}$ was placed under the piston of the hydraulic jack to record the load. A steel beam of height $100 \mathrm{~mm}$ was placed at the top of the CCIB masonry walls to safeguard the uniform application of the load. A total number of four linear variable differential transducers (LVDT) were installed to measure the deformation of the CC-IBM walls under the applied load (Figure 4).

\section{LVDT at mid-span}

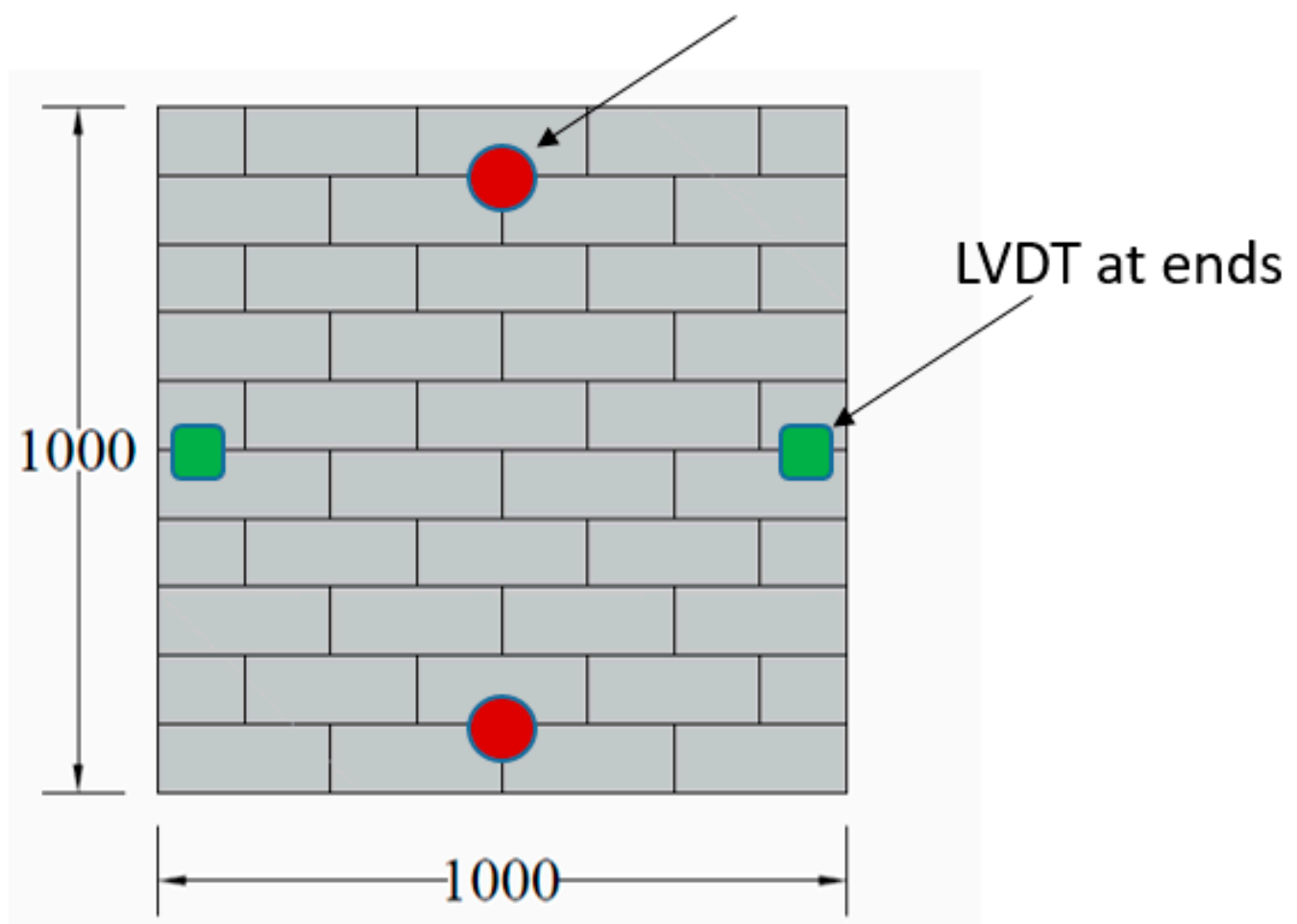

Figure 4. Details of LVDTs (units, mm). 


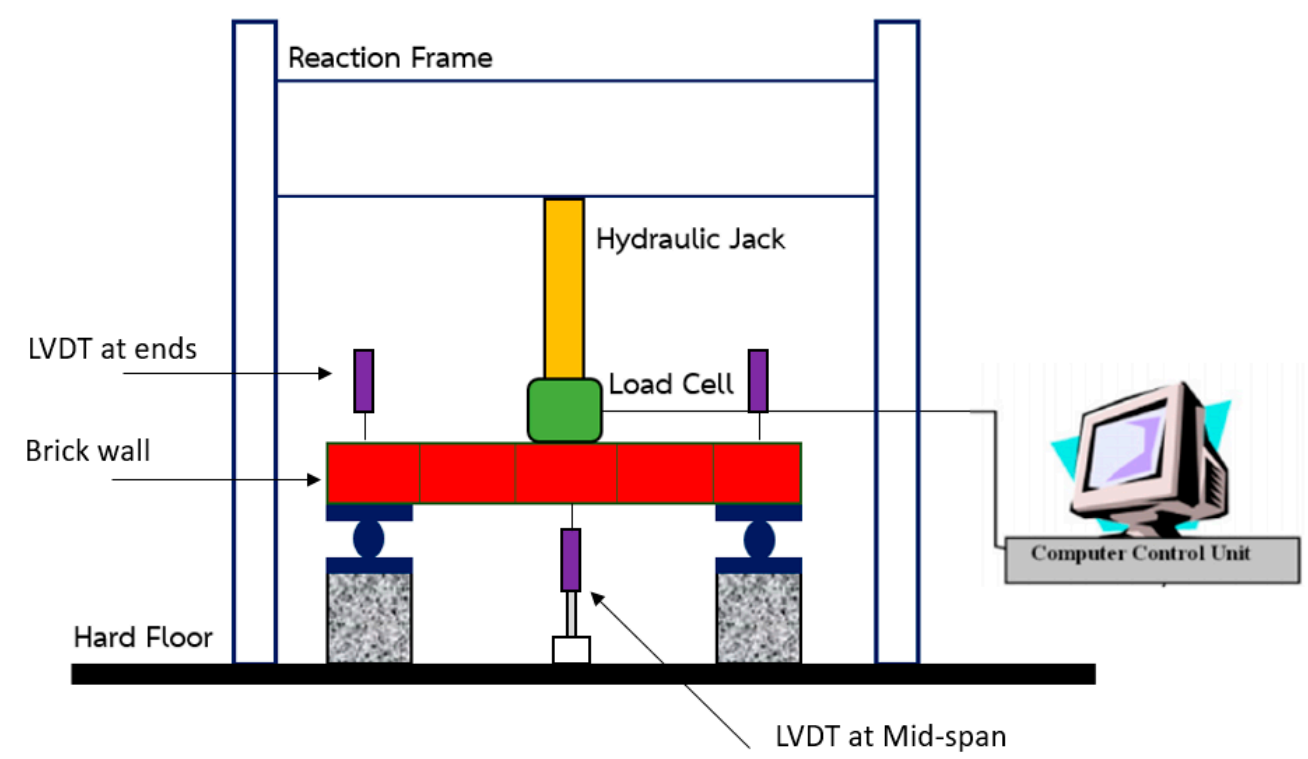

Figure 5. Typical loading setup.

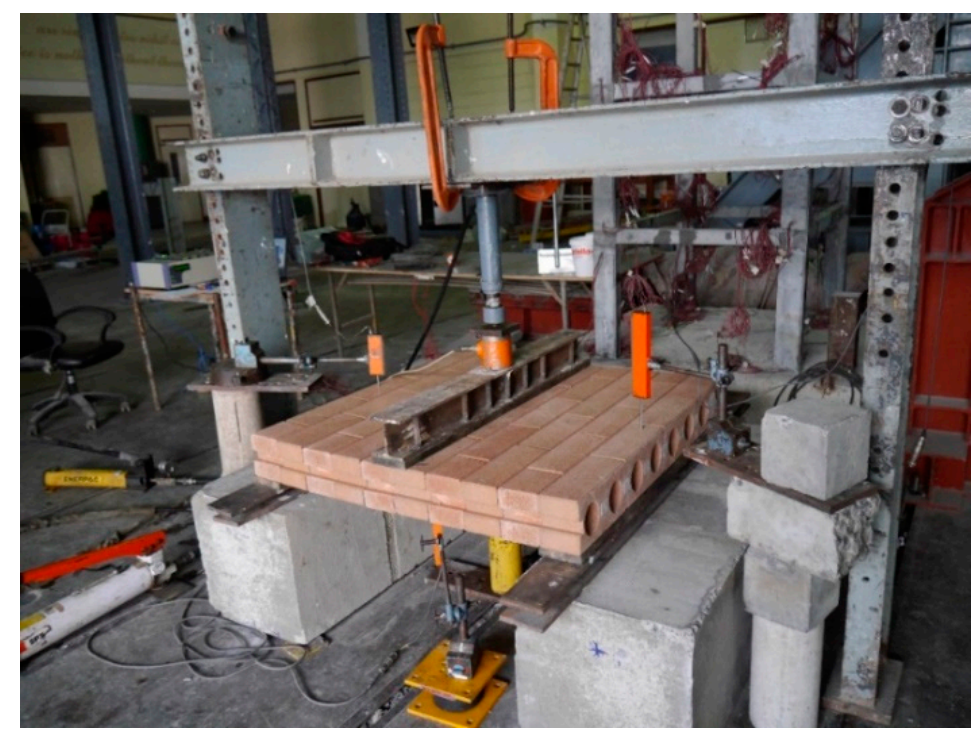

Figure 6. Loading setup (laboratory view).

\section{Experimental Results}

The experimental results in terms of ultimate load, \% increase in ultimate load, and ultimate deflection are summarized in Table 3. The experimental load versus deflection responses of the CCIB masonry walls are shown in Figure 7.

Table 3. Experimental results.

\begin{tabular}{cccc}
\hline CCIB Masonry Walls & Ultimate Load (kN) & $\begin{array}{c}\text { \% Increase in } \\
\text { Ultimate Load }\end{array}$ & $\begin{array}{c}\text { Ultimate Deflection } \\
(\mathbf{m m})\end{array}$ \\
\hline MW-CON & 25.06 & - & 45.3 \\
MW-CS10-A & 34.61 & 38 & 26.9 \\
MW-CS20-A & 43.05 & 72 & 22.0 \\
MW-CS10-A-WM-1L & 39.04 & 56 & 40.4 \\
MW-CS20-A-WM-3L & 46.74 & 87 & 6.90 \\
MW-CS20-B-WM-3L & 24.92 & - & 42.5 \\
\hline
\end{tabular}



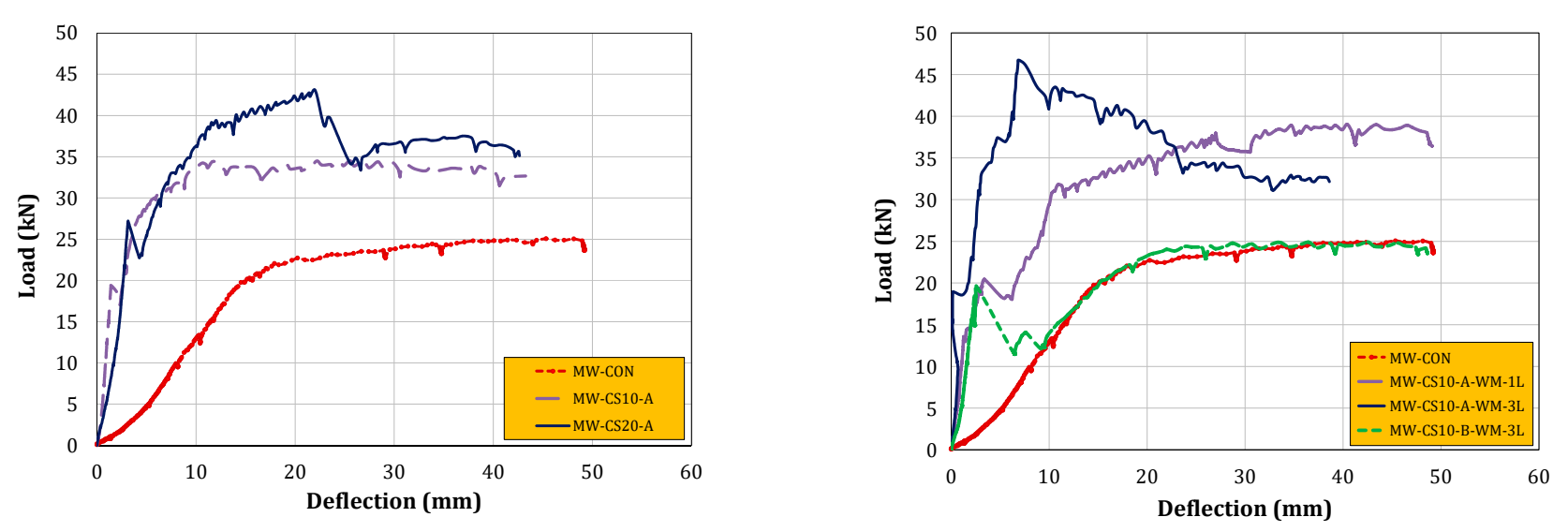

Figure 7. Load versus deflection responses of the CCIB masonry walls.

\subsection{Flexural Capacity of the CCIB Masonry Walls}

The use of cement-sand mortar and wire mesh effectively modified the flexural capacity and the initial stiffness of the CCIB masonry walls (Figure 7). The recorded ultimate load of reference or control CCIB masonry wall was $25.06 \mathrm{kN}$. The ultimate load-carrying capacity of the CCIB masonry wall (strengthened using only cement-sand mortar of thickness $10 \mathrm{~mm}$ ) was $38 \%$ higher than the control wall, i.e., MW-CON. When the thickness of CS mortar was increased to $20 \mathrm{~mm}$, the flexural capacity of the CCIB masonry wall MW-CS20-A was observed to be $72 \%$ higher than the reference wall and $34 \%$ higher than the CCIB masonry wall MW-CS10-A, respectively. The results indicate that the thickness of CS mortar significantly affected the flexural capacity of CCIB masonry walls.

Moreover, the ultimate load-carrying capacity was further enhanced when the cementsand mortar was applied in combination with the wire mesh. The flexural capacity of the CCIB masonry wall MW-CS10-A-WM-1L was $56 \%$ and $18 \%$ higher than the CCIB masonry walls MW-CON and MW-CS10-A, respectively. This behavior shows that the use of wire mesh effectively enhances the flexural capacity of CCIB masonry walls strengthened with CS mortar and wire mesh.

Similar to the thickness of the CS mortar, it was found that the number of layers of wire mesh also had a significant effect on the flexural capacity of the CCIB masonry walls. The flexural capacity of the CCIB masonry wall MW-CS20-A-WM-3L was $87 \%$ and $21 \%$ higher than the CCIB masonry walls MW-CON and MW-CS10-A-WM-1L, respectively. In the case of the strengthening configuration B (Figure 1), where the CS mortar and wire mesh were applied only on the side of the CCIB masonry wall, the flexural capacity of the CCIB masonry wall was almost equal to the reference wall, i.e., MW-CON. However, the initial stiffness and energy absorption capacity of the CCIB masonry wall MW-CS10-B-WM-3L was observed to be higher than the reference or control wall MW-CON. (Further discussion is provided in the next section).

\subsection{Energy Absorption Capacity of the CCIB Masonry Walls}

The energy absorption capacities of the CCIB masonry walls are summarized in Table 4 . The energy absorption capacity of a CCIB masonry wall was defined as the area under the curve, i.e., load versus deflection curves (Figure 7). It can be seen that the use of cement-sand mortar and wire mesh is very effective in modifying the energy capacity of CCIB masonry walls. The energy absorption capacity of the CCIB masonry wall MWCS10-A was $44 \%$ higher than the control wall, i.e., MW-CON. When the thickness of CS mortar was increased to $20 \mathrm{~mm}$, the energy absorption capacity of the CCIB masonry wall MW-CS20-A was observed to be $56 \%$ higher than the reference wall, i.e., MW-CON and $12 \%$ higher than the CCIB masonry wall MW-CS10-A. The energy absorption capacity of the CCIB masonry wall MW-CS10-A-WM-1L was $69 \%$ and $13 \%$ higher than the CCIB masonry walls MS-CON and MW-CS10-A, respectively. 
Table 4. Energy absorption capacity of the CCIB masonry walls.

\begin{tabular}{cccc}
\hline CCIB Masonry Walls & $\begin{array}{c}\text { Energy Absorption } \\
\text { Capacity } \mathbf{( k N - m m )}\end{array}$ & $\begin{array}{c}\text { \% Increase Energy } \\
\text { Absorption Capacity }\end{array}$ & $\begin{array}{c}\text { Ultimate } \\
\text { Failure Modes }\end{array}$ \\
\hline MW-CON & 948 & - & Flexure \\
MW-CS10-A & 1369 & 44 & Flexure \\
MW-CS20-A & 1482 & 56 & Shear \\
MW-CS10-A-WM-1L & 1603 & 69 & Flexure \\
MW-CS20-A-WM-3L & 1383 & 46 & Shear \\
MW-CS20-B-WM-3L & 1017 & 7 & Flexure-shear \\
\hline
\end{tabular}

In addition, the flexural capacity of the CCIB masonry wall MW-CS10-A-WM-3L was $46 \%$ higher than the CCIB masonry wall MW-CON. The energy capacity of the CCIB masonry wall MW-CS20-B-WM-3L was 7\% higher than the control wall, i.e., MW-CON. It could be noticed that the use of CS mortar and wire mesh on only one side was effective in enhancing the initial stiffness (Figure 7); however, we found that there was a slight increase in the energy absorption capacity. Thus, the latter indicates that the performance of strengthening configuration $\mathrm{A}$ is much better than the performance of strengthening configuration B.

\subsection{End Deflection of the CCIB Masonry Walls}

The experimental results in terms of load versus upward deflections (end deflection) are shown in Figure 8. The term "end deflection" is used to express the upward movement of the masonry walls at the ends or the edges (Figure 4). The maximum end deflection of the control CCIB masonry wall was recorded as $3.99 \mathrm{~mm}$. The use of cement-sand mortar was found to be effective in enhancing the end deflections. The end movement of the CCIB masonry wall MW-CS10-A was $66 \%$ higher than the control or reference CCIB masonry wall.
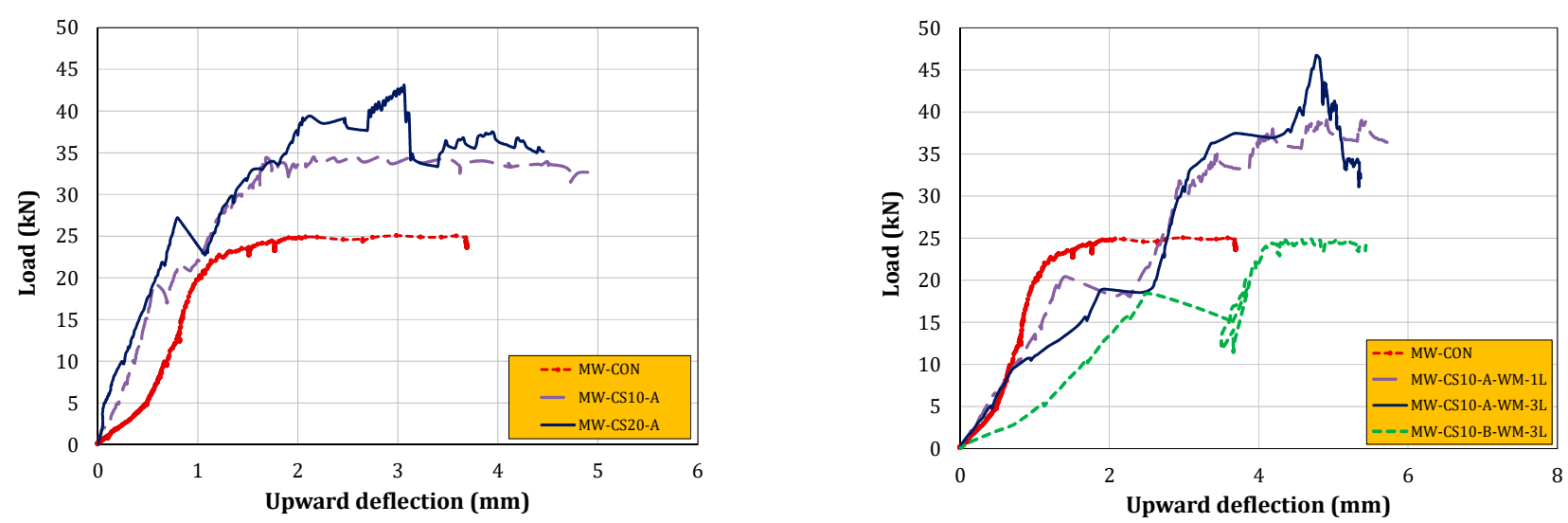

Figure 8. Load versus end deflection responses of the CCIB masonry walls.

In comparison, the end movement of the CCIB masonry wall MW-CS20-A was $49 \%$ higher than the control or reference CCIB masonry wall. In the case of the CCIB masonry wall MW-CS20-A, the end movement was lower than the end movement of the CCIB masonry wall MW-CS10-A. This exception is related to the ultimate failure mode of the masonry wall MW-CS20-A. The ultimate failure of the CCIB masonry wall MW-CS20-A was shear dominated. Therefore, the resulting end movement was lower than the masonry wall MW-CS10-A. The use of wire mesh was also found to be effective in enhancing the end movement. In the case of masonry walls strengthened with CS mortar and wire mesh, the end movements of CCIB masonry walls, i.e., MW-CS10-A-WM-1L and MW-CS20-AWM-3L, were $92 \%$ and $80 \%$ higher than the control masonry wall, respectively. However, the end movement of the CCIB masonry wall MW-CS20-A-WM-3L was recorded lower 
than the CCIB masonry wall MW-CON, which was mainly due to the shear-dominated failure of the masonry wall MW-CS20-A-WM-3L. The end movements were also enhanced when the CS mortar and wire mesh were applied only on one side of the CCIB masonry wall. The end movement of the CCIB masonry wall MW-CS20-B-WM-3L was $82 \%$ higher than the control or reference CCIB masonry wall.

\subsection{Failure Modes of the CСIB Masonry Walls}

The ultimate failure modes of the CCIB masonry walls are shown in Figure 9. The ultimate failure of the CCIB masonry wall MW-CON was mainly due to the joint opening at the mid-span following a large deflection, as shown in Figure 9a. This behavior is an indication that brick joints are very vulnerable against out-of-plane forces. In the CCIB masonry wall, slight splitting and crushing of the cement-clay interlocking bricks were observed at the top under the loading plate. The ultimate failure mode of the CCIB masonry wall CCIB-CS10-A was similar to the control wall MW-CON, i.e., large deflection and joint opening, as shown in Figure 9b. However, in this case, the tensile splitting of the cement-clay interlocking bricks was also observed at the mid-span. Due to the tensile splitting of the cement-clay interlocking brick, the joint opening was also observed on the right side of the mid-span, as shown in Figure 9b. The ultimate failure mode of the CCIB masonry wall CCIB-CS20-A was different from the CCIB masonry walls MW-CON and MW-CS10-A. In this case, large splitting and crushing of the cement-clay interlocking bricks were observed on the right side of the mid-span, i.e., in-between the loading point and the right support, as shown in Figure 9c. This phenomenon could be associated with the large thickness of cement-sand mortar on both sides of the CCIB masonry wall. Due to the cement-sand mortar, the mid-span deflection was considerably reduced, thus, preventing the joint opening at the mid-span and causing the splitting and crushing of the cement-clay interlocking bricks near the support regions. The ultimate failure mode of the CCIB masonry wall MW-CS10-A-WM-1L was also due to the large deflection and joint splitting at the mid-span, as shown in Figure 9d.

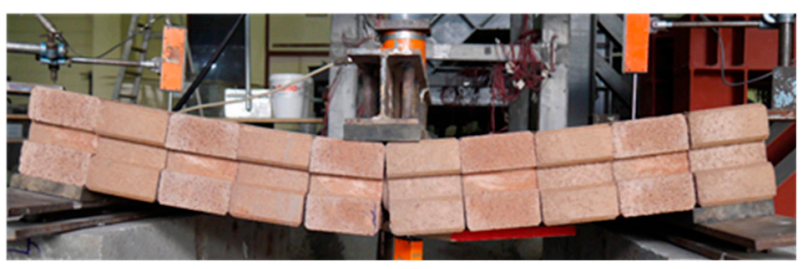

(a)

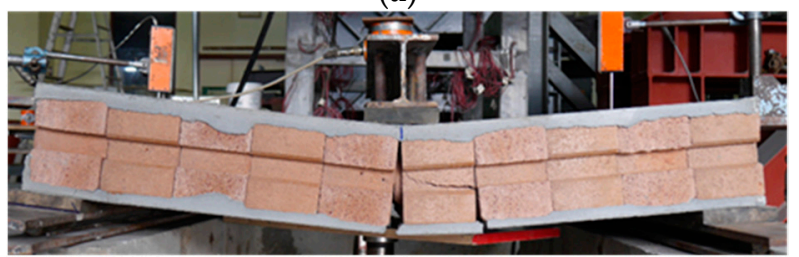

(b)

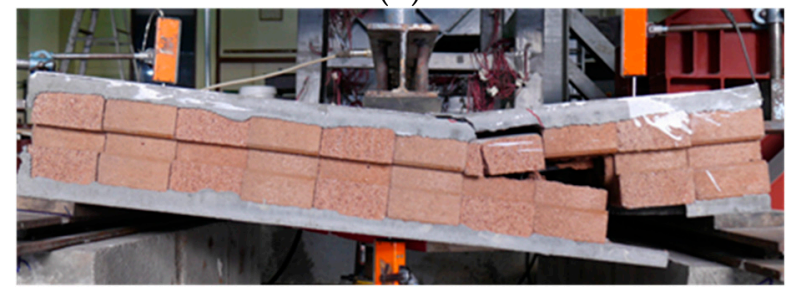

(c)

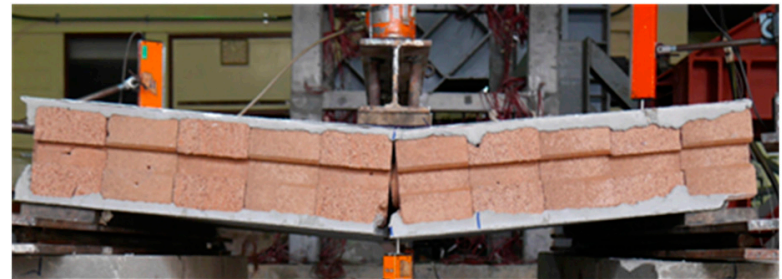

(d)

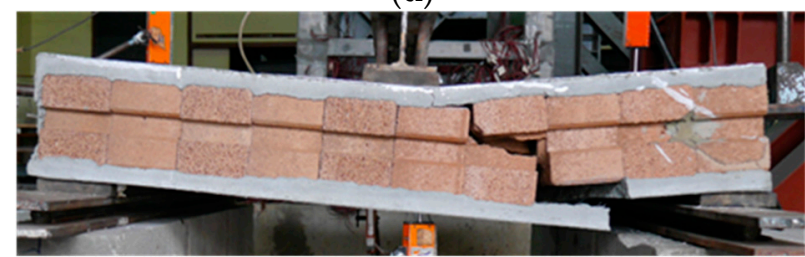

(e)

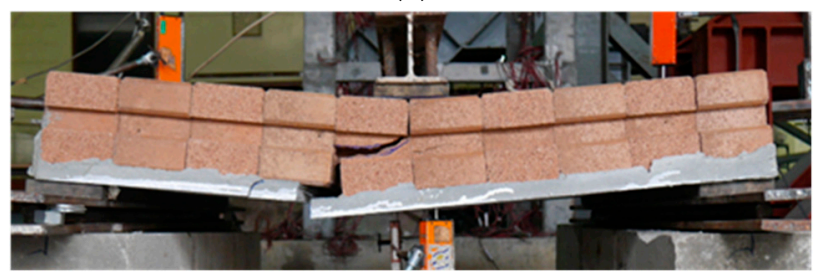

(f)

Figure 9. Ultimate failure modes of the CCIB masonry walls: (a) MW-CON; (b) MW-CS10-A; (c) MW-CS20-A; (d) MWCS10-A-WM-1L; (e) MW-CS20-A-WM-3L; (f) MW-CS20-B-WM-3L. 
In contrast to the CCIB masonry wall MW-CS10-A, in this case, the tensile splitting of the cement-clay interlocking bricks at the mid-span was not observed, which could be associated with the presence of wire mesh in the CCIB masonry wall MW-CS10-A-WM-1L. The presence of the wire mesh could enhance the tensile strength of cement-sand mortar and cement-clay interlocking bricks. The ultimate failure mode of CCIB masonry wall MWCS20-A-WM-3L was similar to the CCIB masonry wall MW-CS20-A (Figure 9e). However, in this case, the splitting and crushing of the cement-clay interlocking bricks were observed over a small region compared to the CCIB masonry wall MW-CS20-A, which could be due to three layers of wire mesh. In the case of the CCIB masonry wall MW-CS20-B-WM-3L, the splitting and crushing of the cement-clay interlocking bricks were observed close to the mid-span, as shown in Figure 9f. This contrary phenomenon is due to the absence of the cement-sand mortar and wire mesh at one side of the CCIB masonry wall MW-CS20-B-WM3L. In addition to the above-discussed failure modes, in all the tested CCIB masonry walls, cement-clay interlocking bricks' tensile splitting was observed at the supports. In general, the ultimate failure modes of the CCIB masonry walls can be divided into three categories, i.e., flexure failure, shear failure, and a combination of both flexure and shear failures, i.e., flexure-shear failure. The failures are defined based on crack initiation, propagation, and ultimate failure modes. A flexure failure represented a failure mode in which vertical cracks were mainly observed at the mid-span, such as MW-CON, MW-CS10-A-WM-1L, and MW-CS10-A-WM-1L. A shear failure represented a failure mode observed by inclined (shearing) cracks near the supporting edge, such as MW-CS20-A and MW-CS20-A-WM-3L. A combination of flexure and shear failure was referred to as flexure-shear failures, such as in the case of MW-CS20-B-WM-3L. The ultimate failure modes of the CCIB masonry walls are summarized in Table 4.

\section{Conclusions}

The use of cement-sand mortar and wire mesh effectively increases the ultimate load-carrying capacity, toughness, and energy absorption capacity of the reinforced CCIB masonry walls.

(1) The increase in ultimate load-carrying capacity and energy absorption capacity is high when the thickness of the cement-sand mortar and layers of wire mesh are increased. The efficiency of the strengthening configuration A was found to be higher than the strengthening configuration $B$.

(2) The highest increases in ultimate load-carrying capacity and energy absorption capacity were observed for masonry wall WM-CS20-A-3L. The flexural capacity of the CCIB masonry wall MW-CS20-A-WM-3L was $87 \%$ and $15 \%$ higher than the CCIB masonry walls MW-CON and MW-CS20-A, respectively.

(3) The ultimate failure mode of control and or reference masonry is attributed mainly due to the large deflections and joint opening at the mid-span. The ultimate failure modes of cement-sand mortar and wire mesh strengthened walls is mainly due to the tensile splitting and crushing of the CCIBs.

(4) In general, the ultimate failure modes of the CCIB masonry walls can be divided into three categories, i.e., flexure failure, shear failure, and a combination of both flexure and shear failures, i.e., flexure-shear failure.

(5) For future research study, the behavior of CCIB masonry walls should be explored when subjected to external reinforcements. In addition, the constitutive models could be developed to comprehend the failure behaviors using analytical and finite element analysis techniques.

(6) According to the experimental results, it can be concluded that using CS mortar and wire-mesh is practical. However, there is a need to evaluate and compare the performance of this method with other techniques. 
Author Contributions: Conceptualization, P.J., Q.H. and K.C.; Data curation, N.A. and Q.H.; Formal analysis, S.V. and H.M.M.; Methodology, M.I.Q., K.C.; Writing-original draft, P.J., N.A., H.M.M. and A.E.; Writing—review \& editing, P.J., S.V., H.M.M., A.E., M.I.Q. and K.C. All authors have read and agreed to the published version of the manuscript.

Funding: The authors of this research work are very grateful to the Srinakharinwirot University, Thailand, for providing research grant (research grant ID 687/2563) to carry out the research work.

Acknowledgments: The authors of this research work are very grateful to the Srinakharinwirot University, Thailand, for providing research grant (research grant ID 687/2563) to carry out the research work. Thanks are also extended to the Asian Institute of Technology (AIT) for the use of their test facilities.

Conflicts of Interest: The authors declare no conflict of interest.

\section{References}

1. Farzampour, A. Compressive Behavior of Concrete under Environmental Effects. In Compressive Strength of Concret; BoD-Books on Demand: Norderstedt, Germany, 2019.

2. Farzampour, A. Temperature and humidity effects on behavior of grouts. Adv. Concr. Constr. 2017, 5, 659.

3. Chalangaran, N.; Farzampour, A.; Paslar, N. Nano Silica and Metakaolin Effects on the Behavior of Concrete Containing Rubber Crumbs. CivilEng 2020, 1, 17. [CrossRef]

4. Chalangaran, N.; Farzampour, A.; Paslar, N.; Fatemi, H. Experimental Investigation of Sound Transmission Loss in Concrete Containing Recycled Rubber Crumbs; Virginia Tech, Virginia Polytechnic Institute and State University: Blacksburg, VA, USA, 2021.

5. Sorrentino, L.; Cattari, S.; Da Porto, F.; Magenes, G.; Penna, A. Seismic behaviour of ordinary masonry buildings during the 2016 central Italy earthquakes. Bull. Earthq. Eng. 2019, 17, 5583-5607. [CrossRef]

6. Moon, L.M.; Griffith, M.C.; Dizhur, D.; Ingham, J.M. Performance of unreinforced masonry structures in the 2010/2011 Canterbury earthquake sequence. In Proceedings of the 15th World Conference on Earthquake Engineering (15WCEE), Lisbon, Portugal, 11 March 2011.

7. Ruangrassamee, A.; Ornthammarath, T.; Lukkunaprasit, P. Damage Due to 24 March 2011 M6.8 Tarlay Earthquake in Northern Thailand. In Proceedings of the 15th World Conference on Earthquake Engineering (15WCEE), Lisbon, Portugal, 24-28 September 2012.

8. Hendry, A.; Khalaf, F.M. Masonry Wall Construction; CRC Press: Boca Raton, FL, USA, 2017.

9. Shakir, A.A.; Mohammed, A.A. Durability Property of Clay Ash, Quarry Dust and Billet Scale Bricks. J. Eng. Sci. Technol. 2015, 10, 591-605.

10. Lenczner, D. Elements of Load Bearing Brickwork; Pergamon Press: Oxford, UK, 1972.

11. Bakhteri, J. Sambasivam, Mechanical Behaviour of Structural Brick Masonry: An Experimental Evaluation. In Proceedings of the 5th Asia-Pacific Structural Engineering and Construction Conference, Johor Bahru, Malasia, 26-28 August 2003; pp. 305-317.

12. Ahmad, A.; Othman, S.Z.; Md Yunus, B.; Mohamed, A. Behaviour of Masonry Wall Constructed using Interlocking Soil Cement Bricks. World Acad. Sci. Eng. Technol. 2011, 60, 1263-1269.

13. Haach, V.G.; Vasconcelos, G.; Lourenço, P.B. Development of a New Test for Determination of Tensile Strength of Concrete Blocks. In Proceedings of the 12th Canadian Masonry Symposium, Mississauga, ON, Canada, 2-5 June 2013.

14. Cascardi, A.; Leone, M.; Aiello, M.A. Transversal joining of multi-leaf masonry through different types of connector: Experimental and theoreticals investigation. Constr. Build. Mater. 2020, 265, 120733. [CrossRef]

15. Joseph, S.; McGarry, B.; Sajjakulnukit, B.; Sopchokchai, O. A Study of Brick Production in Thailand. TDRI Q. Rev. 1990, 5, 11-15.

16. Shakir, A.A.; Naganathan, S.; Mustapha, K.N. Properties of bricks made using fly ash, quarry dust and billet scale. Constr. Build. Mater. 2013, 41, 131-138. [CrossRef]

17. Ravula, M.B.; Subramaniam, J.L. Experimental Investigation of Compressive Failure in Masonry Brick Assemblages Made with Soft Brick. Mater. Struct. 2017, 50, 19. [CrossRef]

18. Sandoval, C.; Calderon, S.; Almazán, J.L. Experimental cyclic response assessment of partially grouted reinforced clay brick masonry walls. Bull. Earthq. Eng. 2018, 16, 3127-3152. [CrossRef]

19. Joyklad, P.; Hussain, Q. Axial compressive response of grouted cement-clay interlocking hollow brick walls. Asian J. Civ. Eng. 2019, 20, 733-744. [CrossRef]

20. Joyklad, P.; Hussain, Q. Performance of Cement Clay Interlocking Hollow Brick Masonry Walls Subjected to Diagonal Compression. J. Eng. Sci. Technol. 2019, 14, 2152-2170.

21. Joyklad, P.; Hussain, Q. Lateral response of cement clay interlocking brick masonry walls subjected to earthquake loads. J. Eng. Sci. Technol. 2020, 15, 4320-4338.

22. Sadek, D.M. Physico-mechanical Properties of Solid Cement Bricks Containing Recycled Aggregates. J. Adv. Res. 2012, 3, 253-260. [CrossRef]

23. Kadir, A.B.A.; Mohajerani, A. Physical and Mechanical Properties of Fired Clay Bricks Incorporated with Cigarette Butts: Comparison between Slow and Fast Heating Rates. Appl. Mech. Mater. 2013, 421, 201-204. [CrossRef] 
24. Theint, P.S.; Ruangrassamee, A.; Hussain, Q. Strengthening of shear-critical RC columns by high-strength steel-rod collars. Eng. J. 2020, 24, 107-128. [CrossRef]

25. Valluzzi, M.; Tinazzi, D.; Modena, C. Shear behavior of masonry panels strengthened by FRP laminates. Constr. Build. Mater. 2002, 16, 409-416. [CrossRef]

26. Turco, V.; Secondin, S.; Morbin, A.; Valluzzi, M.R.; Modena, C. Flexural and shear strengthening of un-reinforced masonry with FRP bars. Compos. Sci. Technol. 2006, 66, 289-296. [CrossRef]

27. Yardim, Y.; Lalaj, O. Shear strengthening of unreinforced masonry wall with different fiber reinforced mortar jacketing. Constr. Build. Mater. 2016, 102, 149-154. [CrossRef]

28. Wahab, N.; Srinophakun, P.; Hussain, Q.; Chaimahawan, P. Performance of concrete confined with a jute-polyester hybrid Fiber reinforced polymer composite: A novel strengthening technique. Fibers 2019, 7, 72. [CrossRef]

29. Joyklad, P.; Suparp, S.; Hussain, Q. Flexural response of JFRP and BFRP strengthened RC beams. Int. J. Eng. Technol. 2019, 11, 203-207. [CrossRef]

30. Chaiyasarn, K.; Hussain, Q.; Joyklad, P.; Rodsin, K. New hybrid basalt/E-glass FRP jacketing for enhanced confinement of recycled aggregate concrete with clay brick aggregate. Case Stud. Constr. Mater. 2021, 14, e00507. [CrossRef]

31. ASTM C1314-1314. Standard Test Method for Compressive Strength of Masonry Prisms; ASTM International: West Conshohocken, PA, USA, 2014.

32. ASTM C1006-07. Standard Test Method for Splitting Tensile Strength of Masonry Units; ASTM International: West Conshohocken, PA, USA, 2007. 